\title{
In vivo Quantification of Abasic Sites for Efficacious Evaluation of DNA- Targeted Chemotherapies
}

\author{
Wenxia Zhu, Chunying Wu, Yuguo Li, Eduardo Somoza, Lili Liu, Stanton Gerson and Yanming Wang* \\ Division of Radiopharmaceutical Science, Case Center for Imaging Research, Department of Radiology, Case Western Reserve University, Cleveland, OH 44106
}

\begin{abstract}
DNA damage and repair represent important biological processes that are targets of various chemotherapies against cancer. In many ways, chemotherapeutic agents can induce DNA damage in cancerous as well as normal cells. However, DNA damage induced by chemotherapeutic agents can be intrinsically repaired by normal physiologic responses, which hampers inhibition of tumor growth and cause drug-resistance. Base excision repair (BER) is one such physiologic process that is important in the cellular response to many chemotherapeutic agents, specifically those agents that target DNAs. Once the BER pathway is triggered, damaged DNA bases undergo a series of chemical modifications resulting in the formation of abasic or apurinic/apyrimidinic (AP) site, which serves as key intermediates in the excision of damaged DNA bases and restoration of regular bases. To monitor BERconferred intrinsic drug-resistance to chemotherapeutic agents such as DNA-alternating temozolomide (TMZ), pemetrexed $\left(\right.$ Alimta $\left.^{\circledR}\right)$, and fludarabine, we have developed a $\mathrm{F}-18$ labeled fluoroethoxyamine $\left(\left[{ }^{11} \mathrm{C}\right] \mathrm{FEX}\right)$ as an imaging agent for positron emission tomography (PET) imaging of DNA damage and repair in vivo. In this work, we report the synthesis, radiolabeling, and evaluation of $\left[{ }^{18} \mathrm{~F}\right] \mathrm{FEX}$ in vivo in mice. We have shown that $\left[{ }^{18} \mathrm{~F}\right] \mathrm{FEX}-$ PET can be used to monitor DNA damage and repair in tumor xenograft mouse models including an uracil DNA glycosylase (UDG)-knockout tumor mouse model of non-small cell lung cancer (NSCLC).
\end{abstract}

Keywords: DNA damage and repair; Positron emission tomography (PET); Apurinic/Apyrimidinic (AP) sites; Imaging

Abbreviations: AP sites: Abasic or Apurinic/Apyrimidinic sites; APE: AP Endonuclease; ARP: Aldehyde Reactive Probe; BER: Base Excision Repair; DIAD: Diisopropylazo-dicaroxylate; $\left[{ }^{18} \mathrm{~F}\right] \mathrm{FEX}$ : F-18 Labeled 2-fluoroethoxyamine; $\left[{ }^{11} \mathrm{C}\right] \mathrm{MX}$ : C-11 Labeled Methoxyamine; N3mA: 3-methyladenine; N7mG: 7-methylguanine; NSCLC: Nonsmall Cell Lung Cancer; SUV: Standardized Uptake Value; TMZ: Temozolomide; UDG: Uracil DNA Glycosylase

\section{Introduction}

Current strategies in cancer treatment are based on inducing DNA damage [1]. Cytotoxic DNA damage that contains altered or misincorporated bases, for example, interferes with DNA metabolic processes and renders cancer cells more vulnerable to damage than normal cells $[2,3]$. In these cells, however, a variety of DNA repair pathways such as base excision repair (BER) counteract the cytotoxic effects of DNA damage. Therefore, if DNA repair pathways can be blocked, the sensitivity of cells to DNA damage can be dramatically modulated [4].

The BER pathway is a major DNA repair mechanism, in which 7-methylguanine (N7mG) and 3-methyladenine (N3mA) DNA adducts induced by temozolomide (TMZ) are repaired. The broad substrate specificity is determined by diverse damage-specific glycosylases $[5,6]$. These glycosylases process damaged bases with high sensitivity and specificity that results in the formation of abasic or apurinic/ apyrimidinic (AP) sites [7]. In fact, AP site formation is a sensitive and specific indicator of DNA damage [8]. In addition to TMZ, nucleoside analogues such as various pyrimidine and purine analogues and antifolates are important antimetabolite compounds that constitute an important class of DNA-targeted anticancer drugs. As they interfere with DNA production, cell division, and growth of tumors, nucleoside analogs are currently used in the clinic to treat many different types of cancer, such as leukemia, lymphoma, colon, breast, lung, and head and neck. For example, pemetrexed (Alimta) is an antimetabolite drug that is widely used in NSCLC $[9,10]$. Pemetrexed inhibits thymidylate synthetase and several key enzymes in the de novo pathways of pyrimidine and purine biosynthesis. This leads to nucleotide pool imbalances that favor incorporation of mismatched bases.

To increase the sensitivity of tumor cells to DNA damage and minimize drug resistance, efforts have been made to inhibit the BER pathway by blocking AP sites. In 1985, methoxyamine (MX) was first introduced as a BER inhibitor by Lizzi and Rosenzweig [11]. Since then, MX has been systematically studied to develop combinatory therapies aimed at enhancing the efficacy of chemotherapeutic agents $[12,13]$. The specific action of MX in the disruption of BER is shown in Figure 1, where MX reacts with the tautomeric open-ring form of deoxyribose when an abnormal base is removed by any one of the DNA glycosylases. The reaction of MX with AP sites is fast, even faster than the downstream repair by apurinic/apyrimidinic endonuclease (APE) [14]. The inhibitory effect of MX on DNA repair results from chemical modification of AP sites as APE substrates, rather than from poisoning of APE enzyme $[15,16]$. It is a merit of MX that produces less cytotoxicity towards normal cells compared to any protein inhibitor that directly disrupts normal enzymatic or kinase activity. It has been

\footnotetext{
*Corresponding author: Yanming Wang, PhD, Division of Radiopharmaceutical Science, Case Center for Imaging Research, Department of Radiology, Case Western Reserve University, Cleveland, OH 44106, USA, Tel: 216844 3288; Fax: 2168448062 E-mail: yanming.wang@case.edu

Received January 03, 2012; Accepted February 22, 2012; Published February 24, 2012

Citation: Zhu W, Wu C, Li Y, Somoza E, Liu L, et al. (2012) In vivo Quantification of Abasic Sites for Efficacious Evaluation of DNA-Targeted Chemotherapies. J Cancer Sci Ther S5:006. doi:10.4172/1948-5956.S5-006

Copyright: (c) 2012 Zhu W, et al. This is an open-access article distributed under the terms of the Creative Commons Attribution License, which permits unrestricted use, distribution, and reproduction in any medium, provided the original author and source are credited.
} 


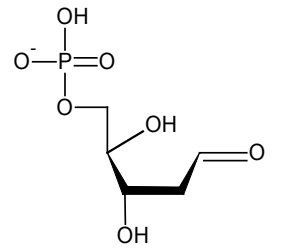

AP-DNA Standard

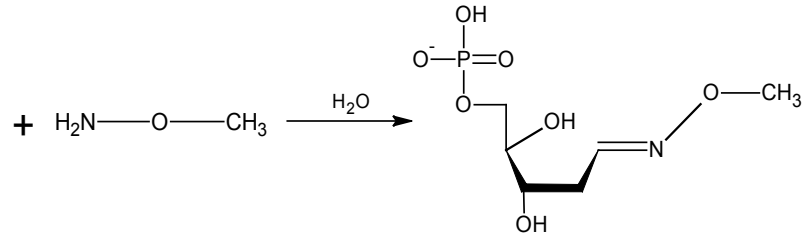

MX
MX-AP-DNA Complex

Figure 1: Postulated mechanism of the binding of methoxyamine to AP sites.

postulated that MX blocks action of APE in one of two ways: either MX's chemical structural alters the AP site by forming a covalent linkage with its aldehyde moiety so that the APE cannot recognize the modified MX-AP site, or the MX-AP site renders the phosphodiester bonds adjacent to the AP site refractory to the catalytic activity of the APE even though the enzyme can still bind to the site.

A major challenge in cancer chemotherapy is to access patient response soon after initial treatment. Since formation of AP sites has been shown to be a sensitive and specific indicator of DNA damage, it can be used as a biomarker to evaluate the efficacy of chemotherapeutic agents $[7,8]$. If patients do not exhibit elevated AP-site formation in tumor regions, significant DNA damage was likely not induced, and the patient probably will not respond to the given chemotherapeutic drug. In such cases, patients should be switched promptly to a different drug. If patients do exhibit elevated AP site formation in tumor regions, it is likely that significant DNA damage was induced in tumor regions. This will make it possible to subsequently modulate the sensitivity of cells to DNA damage by blocking the DNA repair pathways. Such combination chemotherapy could be more effective than single-agent chemotherapy and may lead to a significant increase in cancer cure rates.

To address this unmet need in cancer therapy, the call for direct imaging and quantitative assessment of AP sites in vivo is great. If patients do respond to a given DNA-damaging chemotherapy, in vivo imaging of AP formation will permit determination of the dose and time schedules for maximal efficacy. BER inhibitors will be most effective if administered at the time when AP formation peaks. These imaging studies will also facilitate development of BER inhibitors to potentiate the efficacy of DNA-damaging drugs. Thus, image-guided prognosis and staging will allow clinicians to find the most effective treatment quickly, and this benefit is paramount as early treatment is often the key to effective cancer treatment.

For this purpose, we have developed the capability to radiolabel methoxyamine with positron-emitting carbon-11 and use it as radiotracer for PET to directly detect and quantify AP sites [17]. This allows us to monitor the formation and persistence of AP sites as well as the enhancement of drug-drug synergy by optimizing the formation and persistence of these DNA-bound AP sites after treatment with the combination of chemotherapeutic agents. In order to enhance the potential for clinical applications of this imaging technique and to optimize the potency and specificity of binding to AP sites, we have developed 2-fluoromethoxyanime, termed FEX, which can be labeled with F-18. Compared with $\left[{ }^{11} \mathrm{C}\right] \mathrm{MX},\left[{ }^{18} \mathrm{~F}\right] \mathrm{FEX}$ exhibits very similar binding properties and pharmacokinetic profiles, and the relatively longer half-life of F-18 ( $\mathrm{t}_{1 / 2} 110 \mathrm{~min} \mathrm{cf}$. $20 \mathrm{~min}$ of C-11) permits distribution to remote imaging facilities that do not have access to an on-site cyclotron. In this study, we report the synthesis, radiolabeling, and evaluation of $\left[{ }^{18} \mathrm{~F}\right] \mathrm{FEX}$ and the subsequent PET imaging studies in tumor xenograft mouse models.

To demonstrate that $\left[{ }^{18} \mathrm{~F}\right] \mathrm{FEX}$ binds specifically to AP sites, we performed additional PET imaging studies in a knockout xenograft model that lacks the expression of uracil DNA glycosylase (UDG). One important function of UDG is to prevent mutagenesis by eliminating uracil from DNA molecules and initiating the BER pathway. For example, treatment of pemetrexed induces imbalance of the nucleotide pool, resulting in mis-incorporation of uridine into DNA. In the presence of UDG, the mis-incorporated uridine is removed and an AP site is formed. In the absence of UDG, no AP site is formed and the uracil BER pathway is not initiated. Thus, after pemetrexed treatment, AP sites are expected to be higher in UDG-expressing tumors with sufficient UDG activity. In contrast, AP sites are expected to be lower in UDG-knockout tumors. Thus, tumor xenografts bearing both UDGexpressing tumors and UDG-knockout tumors were treated with pemetrexed. Formation of AP sites was then quantified and compared after PET imaging to determine the in vivo binding specificity of $\left[{ }^{18} \mathrm{~F}\right]$ FEX.

\section{Materials and Methods}

\section{Chemical synthesis}

All of the chemical reagents and solvents were purchased from Sigma Aldrich and used without further purification. NMR spectra were recorded on Varian Inova AS400 spectrometer at $400 \mathrm{MHz}$ for ${ }^{1} \mathrm{H}-\mathrm{NMR}$ and $100 \mathrm{MHz}$ for 13C-NMR. Chemical shifts are presented in ppm on the $\delta$ scale relative to TMS or solvent peak. High resolution mass spectra were recorded using Thermo Scientific LTQ-FT. (University of Cincinnati Mass Spectrometry Facility).

\section{Synthesis of 2-fluoroethoxyamine}

N-(2-Fluoroethoxy) phthalimde (2): To a solution of 2-fluoroethanol (1.28 g, $20 \mathrm{mmol}), \mathrm{N}$-hydroxyphthalimide $(3.50$ g, $21.5 \mathrm{mmol})$, and $\mathrm{PPh}_{3}(5.98 \mathrm{~g}, 22.37 \mathrm{mmol})$ in dry THF $(100 \mathrm{ml})$, diisopropylazo-dicaroxylate (DIAD) was added drop-wise in an icewater bath. The mixture was stirred from $0^{\circ}$ to RT overnight, then concentrated in vacuum and purified on a silica chromatography column (Hexanes/Ethyl Acetate=9:1, V/V) to give compound 2 (3.71 g, $88 \%) .{ }^{1} \mathrm{H}-\mathrm{NMR}\left(400 \mathrm{MHz}, \mathrm{CDCl}_{3}\right) \delta 7.86-7.73(\mathrm{~m}, 4 \mathrm{H}), 4.83(\mathrm{t}, 1 \mathrm{H})$ $4.72(\mathrm{t}, 1 \mathrm{H}), 4.50(\mathrm{t}, 1 \mathrm{H}), 4.43(\mathrm{t}, 1 \mathrm{H}) ;{ }^{13} \mathrm{C}-\mathrm{NMR}\left(100 \mathrm{MHz}, \mathrm{CDCl}_{3}\right) \delta$ $163.29,134.57,128.72,123.61,82.23,80.53,76.81,76.61$.

2-Fluoroethoxyamine (3): Hydrazine monohydrate $(0.725 \mathrm{ml}, 15$ $\mathrm{mmol}$ ) was added dropwise to a solution of compound 2 (1.58 g, 7.5 $\mathrm{mmol})$ in a mixture of dichloromethane (DCM) $(30 \mathrm{ml})$ and methanol 
$(2 \mathrm{ml})$ and the mixture was stirred at $\mathrm{RT}$ for $2 \mathrm{hr}$. The resulting mixture with precipitate was filtered and the filtrate was washed with saturated sodium bicarbonate $(20 \mathrm{ml})$. The aqueous layer was extracted with $\mathrm{DCM}(30 \mathrm{ml} \times 3)$ and the organic extract was dried over anhydrous $\mathrm{Na}_{2} \mathrm{SO}_{4}$. To the dry solution $1 \mathrm{M} \mathrm{HCl}$ in ether $(30 \mathrm{ml})$ was added then the whole mixture was concentrated under vacuum. The white solid was washed with dry DCM and dry ether to get a pure white solid, compound 3 (419 mg, 47\%). 1HNMR (400MHz, DMSO-d6) $\delta 11.17$ (br s, 3H), $4.62(\mathrm{t}, 1 \mathrm{H}), 4.57(\mathrm{t}, 1 \mathrm{H}), 4.30(\mathrm{t}, 1 \mathrm{H}), 4.23(\mathrm{t}, 1 \mathrm{H}) ; 13 \mathrm{CNMR}$ (100MHz, DMSO-d6) $\delta 81.55,79.89,73.36,73.177$. HR-ESIMS: $\mathrm{m} / \mathrm{z}$ calculated 80.05062, found: 80.05052 .

\section{Synthesis of the precursor for F-18 radiolabeling of} 2-fluoroethoxyamine

N-(2-Hydroxyethoxy) phthalimde (4): To a solution of $\mathrm{N}$-Hydroxyphthalimide (1.63 g, $10 \mathrm{mmol})$ and potassium carbonate (5.52 g, $40 \mathrm{mmol}$ ) in $20 \mathrm{ml}$ dry DMSO under argon, 2-bromethanol $(2.0 \mathrm{~g}, 1.6 \mathrm{mmol})$ was added. Then the whole mixture was stirred for $1.5 \mathrm{hr}$ at $70^{\circ} \mathrm{C}$ until the red solution turned almost colorless. Heating was stopped and the reaction mixture was cooled to RT. $200 \mathrm{ml}$ water was added to the mixture and extracted by DCM $(50 \mathrm{ml} \times 3)$ and the extraction was washed $3 \mathrm{X}$ with $2 \mathrm{~N} \mathrm{HCl}$, water, and brine ( $50 \mathrm{ml}$ each). It was then dried over anhydrous sodium sulfate and concentrated under reduced pressure in a rotary evaporator. Purification was achieved by eluting on a silica column (Hexanes/Ethyl Acetate $=1.5: 1, \mathrm{~V} / \mathrm{V})$, yielding $1.554 \mathrm{~g}$ of the product, compound $4(75 \%) .{ }^{1} \mathrm{HNMR}\left(400 \mathrm{MHz}, \mathrm{CDCl}_{3}\right)$ $\delta$ 7.8-7.77 (m, 4H), $4.40(\mathrm{~m}, 2 \mathrm{H}), 3.79(\mathrm{~m}, 2 \mathrm{H}){ }^{13} \mathrm{CNMR}(100 \mathrm{MHz}$, $\mathrm{CDCl}_{3}$ ) $\delta 163.25,134.59,128.57,123.56,77.32,40.24$. (HR-ESIMS: $\mathrm{m} / \mathrm{z}$ calculated 207.14238, found: 207.18280).

N-(2-Tosylethoxyl) phthalimde (5): Compound (4) (110 mg, 0.53 $\mathrm{mmol}$ ) was dissolved in $10 \mathrm{ml}$ anhydrous pyridine at $0^{\circ} \mathrm{C}$. After stirring for $2 \mathrm{hr}$, $p$-toluenesulfonyl chloride $(133 \mathrm{mg}, 6.9 \mathrm{mmol}$ ) was added and the ice bath was removed. After reaction for another $8 \mathrm{hrs}$ at room temperature, the reaction mixture was transfered to a separatory funnel $(250 \mathrm{ml})$ and was extracted $3 \mathrm{X}$ using $75 \mathrm{ml}$ of diethyl ether. The organic layers were washed sequentially with $100 \mathrm{ml}$ cold $1 \mathrm{~N} \mathrm{HCl}, 100 \mathrm{ml}$ water, and $100 \mathrm{ml}$ brine. The combined solution was dried over anhydrous sodium sulfate. After concentration under reduced pressure, the tosylate product was used without further purification. (187 mg, 98\%). ${ }^{1} \mathrm{HNMR}\left(400 \mathrm{MHz}, \mathrm{CDCl}_{3}\right) \delta$ 7.82-7.74 (m, 6H), 7.34-7.31 (m, 2H), $4.43-4.38(\mathrm{~m}, 4 \mathrm{H}), 2.43(\mathrm{~s}, 3 \mathrm{H}){ }^{13} \mathrm{CNMR}\left(100 \mathrm{MHz}, \mathrm{CDCl}_{3}\right) \delta 163.29$, $145.023,134.62,132.46,129.85,128.66,128.02,123.64,75.06,67.09$. (HR-ESIMS: $\mathrm{m} / \mathrm{z}$ calculated 381.05123, found: 381.15146 ).

\section{Radiosynthesis of $\left[{ }^{18} \mathrm{~F}\right] \mathrm{FEX}$}

$\left[{ }^{18} \mathrm{~F}\right]$ fluoride was generated by an on-site Scanditronix MC-17 cyclotron. The $\left[{ }^{18} \mathrm{~F}\right] \mathrm{F}^{-}$was trapped in an anion sep-pack column, then rinsed into a vial by $\mathrm{K} 222 / \mathrm{K}_{2} \mathrm{CO}_{3}$ in acetonitrile and water solution (acetonitrile:water 4:1). After azotropic distillation 3 times, N-(2thosylethoxyl) phthalimide (5) dissolved in anhydrous acetonitrile was added into a vial. The reaction mixture was then stirred for 10 min to produce $\mathrm{N}-\left(2-\left[{ }^{18} \mathrm{~F}\right]\right.$ fluoroethoxy) phthalimde (2), which was confirmed by HPLC with the same retention time of unlabeled $\mathrm{N}-(2$ fluoroethoxy) phthalimde. The phthalimide was then deprotected by hydrazine monohydrate in methylene chloride for $10 \mathrm{~min}$ at room temperature. The reaction mixture was extracted by ethyl acetate $(2$ $\mathrm{ml} \times 2)$, and the organic extraction was washed with $\mathrm{H}_{2} \mathrm{O}(1 \mathrm{ml} \times 2)$.
After concentration (less than $2 \mathrm{ml}$ ), the crude product was purified by high pressure liquid chromatography (HPLC) on a semi-preparative HPCL column (Luna $5 \mathrm{~m} \mathrm{C18} 250 \mathrm{~mm} \times 10 \mathrm{~mm}$ ). The mobile phase was $\mathrm{CH}_{3} \mathrm{CN} / \mathrm{H}_{2} \mathrm{O}=75 \%: 25 \%$ with a flow rate of $3 \mathrm{ml} / \mathrm{min}$ and the retention time was $6.38 \mathrm{~min}$. The peak of the F-18 labeled FEX was characterized and confirmed by HPLC through co-injection with the cold standard.

\section{Biochemical Assay Based on Aldehyde Reactive Probe (ARP)}

The ARP assays were performed as previously described with minor modifications [1]. Briefly, following pemetrexed treatment for $24 \mathrm{hrs}$ NSCLC cells were harvested and cellular DNAs were extracted by phenol (Fischer Scientific, Fair Lawn, NJ) and chloroform (SigmaAldrich, St Louis, MO). Cellular DNA $(10 \mu \mathrm{g})$ was incubated with $15 \mu \mathrm{l}$ of $1 \mathrm{mM}$ aldehyde reactive probe (ARP, Dojindo Laboratories, Kumamoto, Japan) in $135 \mu \mathrm{l}$ PBS solution at $37^{\circ} \mathrm{C}$ for $15 \mathrm{~min}$. DNA was then precipitated by adding $400 \mu \mathrm{l}$ ice-cold ethanol (100\%) at $-20^{\circ} \mathrm{C}$ for $20 \mathrm{~min}$ and washed once with $70 \%$ ethanol. DNA was dried at room temperature for $30 \mathrm{~min}$ and then re-suspended in TE buffer to achieve a final concentration of $0.3 \mu \mathrm{g} / 100 \mu \mathrm{l}$. The ARP-labeled DNA was then heat-denatured at $100^{\circ} \mathrm{C}$ for $5 \mathrm{~min}$, quickly chilled on ice and mixed with an equal amount of $2 \mathrm{M}$ ammonium acetate. The DNA was then immobilized on BA-S 85 nitrocellulose membrane (Schleicher and Schuell, Dassel, Germany) using a minifold II vacuum filter device (Schleicher and Schuell, Dassel, Germany). The membrane was baked at $80^{\circ} \mathrm{C}$ for $1 \mathrm{hr}$ and incubated with $0.25 \%$ BSA/PBS containing streptavidin-conjugated horseradish peroxidase (BioGenex, SanRamon, CA) at room temperature for 40 min with gentle shaking. ARP-labeled AP sites were visualized by chemiluminescence (Amersham Corp, Piscataway, NJ) followed by quantitative densitometry using $\mathrm{NIH}$ Image software.

\section{Preparation of the Animal Models through Intracranial Tumor Implantation}

Tumor cells $\left(5 \times 10^{6}\right)$ were injected into the flanks of female athymic HSD nude mice, at 6-8 weeks of age. The tumors were measured with calipers using the National Cancer Institute formula: $\mathrm{V}=\mathrm{L}(\mathrm{mm}) \mathrm{I}^{2}$ $(\mathrm{mm}) / 2$ where $\mathrm{L}$ is the largest diameter and $\mathrm{I}$ is the smallest diameter of the tumor. When the volume of tumor nodules reaches about 100$150 \mathrm{~mm}^{3}$, the tumor-bearing mice were used for experiments.

\section{Preparation of UDG-knockout model}

The tumor xenografts were derived from paired cell lines DLD1 UDG +/+/DLD1 UDG-/- cells. UDG null cells were generated by gene disruption via homologous recombination. Briefly, rAAV targeting vectors were constructed by insertion of left homology arm (LA) and right homology arm (RA) into the rAAV-Neo-LoxP vector. Targeted rAAV viruses were packaged in 293 T cells. The virus was harvested and used to infect target cells. Cells were then treated with G418 (geneticin) to select for resistant clones. These clones were then screened for homologous recombination with PCR using primers complementary to sequences in the neomycin resistance gene and upstream of the left homology arm (indicated as LA-F and LA-R). Confirmative PCR was also performed on G418 resistant clones using primers complementary to the neomycin resistance gene and to a sequence downstream of the RA (indicated as RA-F and RA-R). The neomycin gene cassette was 
Citation: Zhu W, Wu C, Li Y, Somoza E, Liu L, et al. (2012) In vivo Quantification of Abasic Sites for Efficacious Evaluation of DNA-Targeted Chemotherapies. J Cancer Sci Ther S5:006. doi:10.4172/1948-5956.S5-006

Page 4 of 7

excised by infecting target clones with adenovirus expressing Crerecombinase. Genomic PCR to amplify 178 bp fragments surrounding the LoxP insertion site (PC-F and PC-R) was used for the final screening.

\section{MicroPET Imaging}

MicroPET studies were conducted in a Concord R4 microPET scanner under anesthesia with $2.0 \%$ isoflurane carried by oxygen gas. The dynamic PET image acquisition was performed immediately after tail vein injection of $\left[{ }^{18} \mathrm{~F}\right] \mathrm{FEX}(\sim 300 \mu \mathrm{Ci}$ for each mouse $)$ over $90 \mathrm{~min}$ in a list mode of emission acquisition. This was followed by $10 \mathrm{~min}$ transmission acquisition using ${ }^{57} \mathrm{Co}$ which was used for attenuation correction. A heating lamp was used to maintain the animals' body temperature around $34^{\circ} \mathrm{C}$.

\section{MRI Imaging}

MRI scans were performed immediately after the microPET scans while the animals were still under anesthesia to keep the positions of the mice unchanged.

MR image acquisition was conducted on a Bruker BioSpec horizontal magnet (7T; $30 \mathrm{~cm}$ bore) with a transmit/receive rat volume coil. Two mice were mounted on the holder for each scan under the anesthesia consisting of $2 \%$ isofluorane and $98 \%$ oxygen. The sequence is $\mathrm{T} 2$-weighted turbo spin echo $(\mathrm{TR} / \mathrm{TE}=3000 / 60 \mathrm{~ms}$, resolution $=$ $1 \mathrm{~mm} \times 200 \mu \mathrm{m} \times 200 \mu \mathrm{m})$. During the acquisition, the respiration rates of the mice were monitored and regulated within the range of $30-40 \mathrm{breath} / \mathrm{min}$ by adjusting the percentage of isofluorane, while the animals' body temperature was kept around $34^{\circ} \mathrm{C}$ by thermal control of warm air directly from the magnet core. Multi slices of the region of interest were selected in three directions: axial, coronal and sagittal planes.

\section{Quantitative image analysis}

Quantitative image analysis was based on the co-registration of tumor regions defined by MR images with the radiotracer uptake determined by microPET scans. The in vivo pharmacokinetic profile of $\left[{ }^{18} \mathrm{~F}\right] \mathrm{FEX}$ in tumor regions was analyzed in terms of $\left[{ }^{18} \mathrm{~F}\right] \mathrm{FEX}$ uptake and retention according to the co-registered images. The radioactivity concentration in the tumor tissues is represented by means of standardized uptake value (SUV) $[(\mu \mathrm{Ci} / \mathrm{cc}) /(\mu \mathrm{Ci} / \mathrm{g})]$ as a function of time.

\section{Results}

\section{Chemical synthesis}

The chemical synthesis of FEX is shown in Scheme 1. For the synthesis of 2-fluoroethoxylamine, N-hydroxyphthalimide was used as the starting material to react with 2 -fluoroethanol via the Mitsunobu reaction to produce N-(2-fluoroethoxy) phthalimde (2) in $88 \%$ yield. Then compound 2 reacted with hydrazine monohydrate in dry methylene chloride at room temperature for $2 \mathrm{hr}$ to give 2 -fluoroethoxylamine in form of its hydrochloride salt in $47 \%$ yield.

For synthesis of the radiolabling precursor, $\mathrm{N}$-(2-thosylethoxyl) phthalimde (5), N-hydroxyphthalimide was coupled with 2-bromethanol under basic condition at $90^{\circ} \mathrm{C}$ for $2 \mathrm{hr}$ to yield $\mathrm{N}$ - (2hydroxyethoxy) phthalimde (4) in 75\% yield. Then, compound 4 was tosylated using $p$-toluenesulfonyl chloride in the presence of dry pyridine from $0^{\circ} \mathrm{C}$ to room temperature over $6 \mathrm{hr}$. After the general workup, the tosylated compound 5 was sufficiently pure to use without further purification (98\% yield).

\section{Radiosynthesis}

$\left[{ }^{18} \mathrm{~F}\right] \mathrm{FEX}$ was successfully radiolabeled in two steps starting with $\left[{ }^{18} \mathrm{~F}\right]$ fluoride [18]. The first step was to covert $\mathrm{N}$-(2-thosylethoxyl) phthalimde (5) to $\mathrm{N}-\left(2-\left[{ }^{18} \mathrm{~F}\right]\right.$ fluoroethoxyphthalimde (2) in the presence of $\mathrm{K} 222$ and $\mathrm{K}_{2} \mathrm{CO}_{3}$ in acetonitrile and water $(\mathrm{V}: \mathrm{V}=8: 2)$ at $95^{\circ} \mathrm{C}$ for $10 \mathrm{~min}$. The second step was to remove the protecting group using hydrazine monohydrate in methylene chloride at room temperature for 15 min to give $2-\left[{ }^{18} \mathrm{~F}\right] \mathrm{FEX}$ (3). After extraction with ethyl acetate

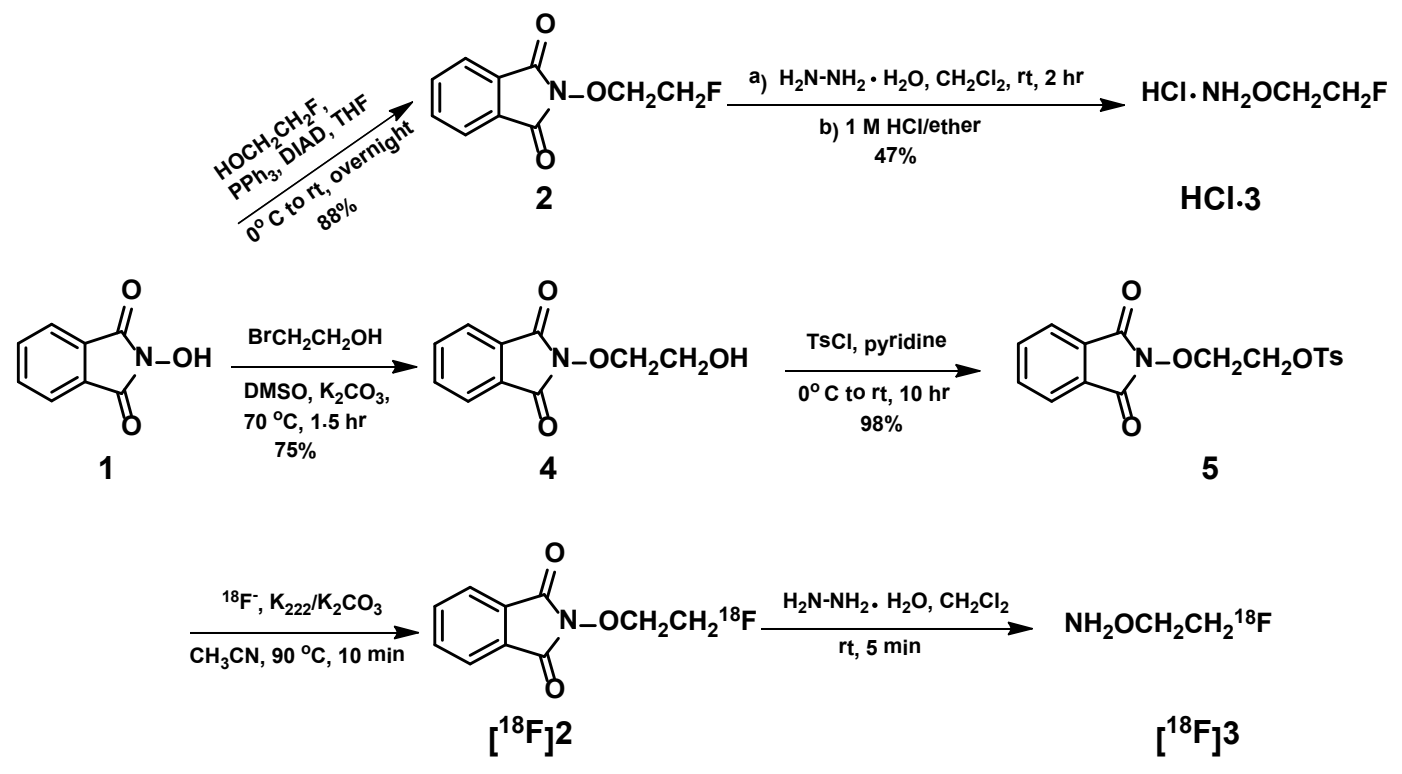

Scheme 1: Chemical synthesis and F-18 radiolabeling of FEX. 
$(5 \mathrm{ml} \times 3)$ and evaporation, the crude $\left[{ }^{18} \mathrm{~F}\right] \mathrm{FEX}$ was purified by HPLC (Luna $5 \mu \mathrm{m} \mathrm{C18} 250 \mathrm{~mm} \times 10 \mathrm{~mm}, \mathrm{CH}_{3} \mathrm{CN}: \mathrm{H}_{2} \mathrm{O}=3: 1$, flow rate: $3 \mathrm{mLmin}^{-1}$, retention time: $6.38 \mathrm{~min}$ ) and confirmed by co-injection with the corresponding cold standards. The total synthesis takes about 75 min with an average final radiochemical yield of $11.6 \%$ after decay correction [19].

\section{ARP-based AP-site binding assay}

To determine the AP site binding potency of FEX, NSCLC cells were treated with different doses of pemetrexed. AP site formation was then measured by the ARP-based assay. NSCLC cells (H460) were treated with pemetrexed alone $(0-400 \mu \mathrm{M})$, pemetrexed plus MX (6 $\mathrm{mM})$, and pemetrexed plus FEX (6 mM) for $24 \mathrm{hr}$. As shown in Figure 2 , formation of AP sites was induced by different doses of pemetrexed. Co-treatment with MX or FEX ( $6 \mathrm{mM})$ significantly reduced the density of free AP sites. Using a dose of $200 \mu \mathrm{M}$ pemetrexed, co-treatment with MX ( $6 \mathrm{mM})$ reduced the amount of AP sites by $56 \%$ while co-treatment with FEX reduced the amount of AP sites by $52 \%$. Using a dose of 400 $\mu \mathrm{M}$ pemetrexed, co-treatment with $\mathrm{MX}(6 \mathrm{mM})$ reduced the amount of AP sites by $43 \%$ while co-treatment with FEX reduced the amount of AP sites by $36 \%$. Our preliminary AP site binding results showed that FEX potently bound to AP sites in a way similar to MX (Figure 2).

\section{In vivo imaging studies}

For quantitative analysis of FEX uptake, both microPET and MRI were conducted and the images were coregistered. The tumor tissues $(n=4)$ in the xenografts as detected by high resolution MR images were defined as regions of interest (ROI). As shown in Figure 3, coregistration of MRI and PET images using COMKAT permits quantification of standardized uptake value (SUV) of $\left[{ }^{18} \mathrm{~F}\right] \mathrm{FEX}[20]$.

\section{Imaging of AP-site formation in DLD1 UDG +/+ mouse tumor xenografts}

To examine the binding specificity of $\left[{ }^{18} \mathrm{~F}\right] \mathrm{FEX}$ in vivo, we conducted imaging studies in a DLD1 UDG +/+ melanoma xenograft mouse model that was treated with pemetrexed via i.p. injection 24

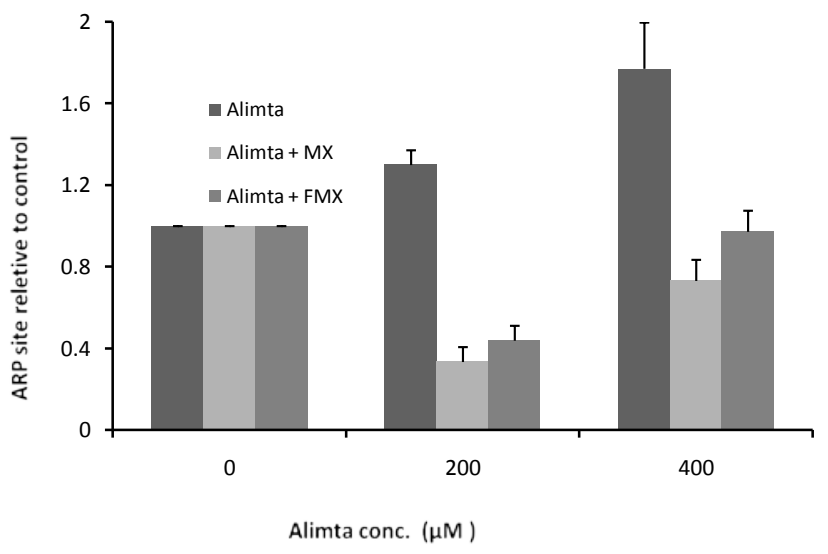

Figure 2: AP sites increased in NSCLC cells after treatment with pemetrexed $\left(\right.$ Alimta $^{\circledR}$ ) in a dose-dependent manner. By using ARP assay, the formation of AP sites in NSCLC cells was measured. Cells were treated with pemetrexed (200 $\mu \mathrm{M}, 400 \mu \mathrm{M})$, pemetrexed $(200 \mu \mathrm{M}, 400 \mu \mathrm{M})$ plus MX $(6 \mathrm{mM})$, pemetrexed $(200$ $\mu \mathrm{M}, 400 \mu \mathrm{M})$ plus FEX (6 mM) for $24 \mathrm{~h}$. Co-treatment by pemetrexed with MX or FEX reduced the amount of AP sites detected by ARP-essays under the same conditions, suggesting that FEX, just as MX, competed with ARP in binding to AP sites induced by pemetrexed.

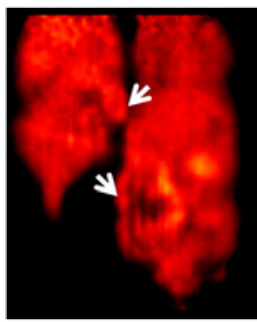

(A)

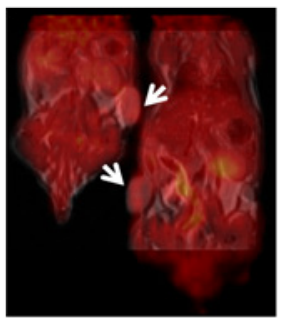

(B)

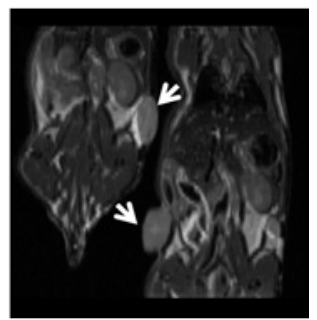

(C)
Figure 3: Coronal view of melanoma xenografts by $7 \mathrm{~T} \mathrm{MRI} \mathrm{and} \mathrm{microPET} \mathrm{co-}$ registration using $\left[{ }^{18} \mathrm{~F}\right] \mathrm{FEX}$ : (A) In vivo PET images; (B) PET-MRI fusion images; (C) In vivo MR images scanned immediately after the PET scan and the animals kept under anesthesia.
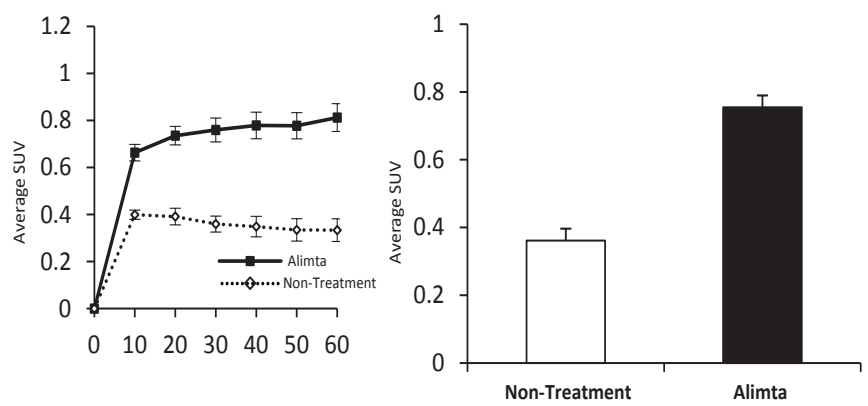

Figure 4: Treated mouse received pemetrexed (Alimta ${ }^{\circledR}$ ) treatment 24 hours prior to PET imaging. A) Average SUV time curves of pemetrexed treated versus non treated wild type mouse model. B) 60 minute Average SUV values for pemetrexed and non treated wild type mouse model.

hr prior to microPET studies. Following microPET and MRI image acquisition and coregistration, $\left[{ }^{18} \mathrm{~F}\right] \mathrm{FEX}$ uptake in the tumor regions $(n=4)$ was quantified and compared with non-treated regions $(n=4)$. In the treated xenografts, $\left[{ }^{18} \mathrm{~F}\right] \mathrm{FEX}$ uptake was twice that of the nontreated mouse model. The results are well correlated with the treatment effect of pemetrexed which induces AP site formation. The trend of SUV over time and average quantitative uptake of $\left[{ }^{18} \mathrm{~F}\right] \mathrm{FEX}$ in pemetrexed treated and nontreated xenograft tumor mice are shown in Figure 4.

\section{Imaging of AP site formation in the DLD1 UDG -/- mouse model}

For comparison, we also conducted imaging studies in a DLD1 UDG -/- melanoma xenograft mouse model that was also treated with pemetrexed under the same conditions. As shown in Figure 5, there was almost no difference in the uptake of $\left[{ }^{18} \mathrm{~F}\right] \mathrm{FEX}$ in terms of SUV between the pemetrexed-treated and nontreated DLD1 UDG -/- mouse model, which indicates that pemetrexed treatment did not increase the formation of AP sites in the DLD1 UDG -/- mouse model compared to non-treated controls.

Comparison of AP site imaging between DLD1 UDG +/+ and DLD1 UDG -/- mouse models treated with Pemetrexed

To obtain a better comparison of AP site formation in both treated DLD1 UDG +/+ and DLD1 UDG -/- mouse models, microPET and MRI studies were conducted. The results show that AP sites formed in the DLD1 UDG $+/+$ tumor mouse model are $21 \%$ higher than that in the DLD1 UDG -/- tumor mouse model as illustrated by the quantitative analysis in Figure 6 . The difference in SUV is sufficiently 


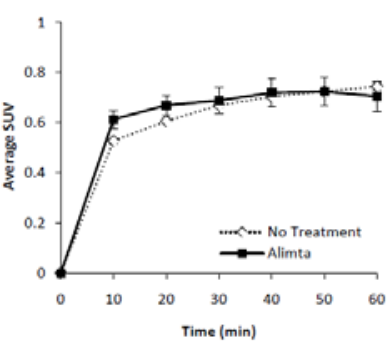

(A)

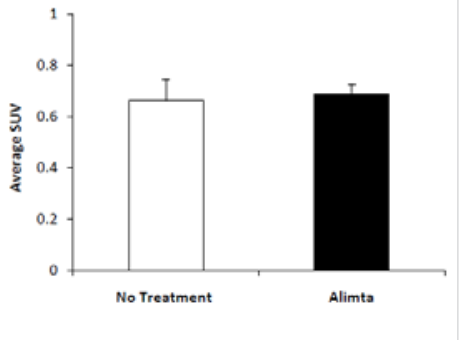

(B)
Figure 5: Treatment and non-treatment of pemetrexed $\left(\right.$ Alimta $\left.^{\circledR}\right)$ in the knockout mouse model. Treated mouse received pemetrexed drug treatment 24 hours prior to PET imaging. A) Average SUV time curves of pemetrexed treated versus non treated knockout mouse model. B) 60 minute Average SUV values for pemetrexed and untreated knockout mouse model.

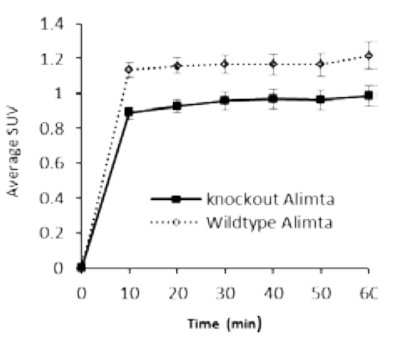

(A)

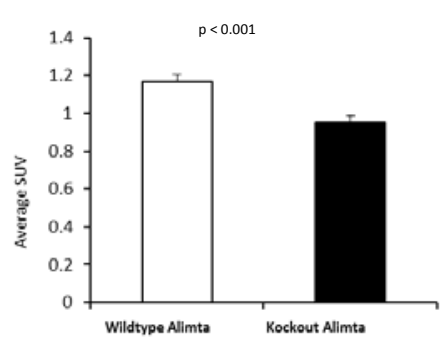

(B)
Figure 6: Treatment of pemetrexed $\left(\right.$ Alimta $\left.{ }^{\circledR}\right)$ on wild type and knock out mouse models. A) Average SUV time curves of wild type versus knockout pemetrexed treated mouse model. B) 60 minute average SUV values for nontreated wild type and knockout pemetrexed treated mice.

significant to show the specific measurement of AP sites induced by pemetrexed.

\section{Discussion}

Fluorinated agents often possess unique biological properties [2124]. Specific interactions between some fluorinated compounds and DNA have shown that incorporation of fluorine into DNA binding agents, the binding affinity is significantly enhanced [25-27]. We thus hypothesize that introduction of fluorine into methoxyamine will facilitate the interaction with DNA and subsequently enhance the potency of binding to AP sites.

For this reason, we incorporated fluorine into methoxyamine through a linker containing two carbons. We also tried to use both a 3- or 4-carbon linker, but this often resulted in elimination of fluorine as a result of intramolecular cyclization forming a 5- or 6-member ring, respectively. For radiolabeling with F-18, the amino group had to be protected in order to carry out the nucleophilic substitution reaction of $\left[{ }^{18} \mathrm{~F}\right] \mathrm{KF}$ with the previously prepared tosylate precursor in the presence of potassium carbonate. For this purpose, we found that phthalimide was an effective protecting group, which could be readily removed subsequently when treated with hydrazine. The potency of FEX for AP sites was evaluated in an ARP-based binding assay that we previously established [28]. Using pemetrexed to induce AP sites in the NSCLC cell line, FEX effectively blocked AP sites induced by pemetrexed. At a dose of $200 \mu \mathrm{M}$ of pemetrexed, $66.6 \%$ of AP sites were blocked by FEX in a way similar to MX( $74.5 \%)$. Thus, incorporation of fluorine did not negatively affect the binding potency of MX.

Encouraged by these results, we conducted microPET imaging studies first in mouse tumor xenografts bearing either DLD1 UDG +/+ or DLD1 UDG -/- tumor tissues. For quantification of $\left[{ }^{18} \mathrm{~F}\right] \mathrm{FEX}$ uptake in tumor tissues, high resolution MR images were also acquired immediately following microPET studies to define the tumor regions. Coregistration of MR images and PET images using COMKAT [20] allowed us to quantify the radioactivity concentration in terms of average SUV as a function of time. Each type of tumor xenograft was imaged before and after pemetrexed treatment for comparison.

Our primary goal is to evaluate the effectiveness of FEX-PET as an imaging marker to monitor the effect of pemetrexed on AP site formation. In order to define the in vivo specificity, we used mouse tumor xenografts bearing either DLD1 UDG +/+ or DLD1 UDG -/tumor tissues. Previous studies have shown that UDG is a critical enzyme involved in the BER pathway for DNA repair. Lack of UDG inhibits the excision of a uracil base, which hampers formation of AP sites.

When the DLD1 UDG +/+ tumors were treated with pemetrexed, $\left[{ }^{18} \mathrm{~F}\right] \mathrm{FEX}$ uptake was significantly increased in the tumor tissues compared to that in non-treated tumor tissues. The increase of FEX uptake suggested that formation of AP sites was drastically elevated (Figure 4). This is the first time that pemetrexed-induced AP-site formation was detected in vivo, which is consistent with previous in vitro studies, which showed that pemetrexed induced DNA damage through the inhibition of thymidylate synthase (TS). Pemetrexed treatment results in reduction of dTTP as well as an increase of dUTP. As a consequence of dUMP accumulation, dUTP levels exceed dUPTase activity. Because the polymerase uses dUTP/dTTP at the same rate, dUTP is eventually incorporated in DNA. With the incorporation of ultra Uracil base, UDG can excise the uracil base from the strands of the DNA, which triggers BER pathways and forms more AP sites [29-31]. The increase of $\left[{ }^{18} \mathrm{~F}\right] \mathrm{FEX}$ uptake clearly showed the effect of pemetrexed in this moue model.

Once UDG is knocked out from the tumor tissues, no difference of FEX uptake could be observed before and after pemetrexed treatment, suggesting that pemetrexed did not induce AP-site formation in the absence of UDG. This is consistent with previous observations that knockout UDG inhibits AP-site formation [32-34].

The comparison of AP site formation between the treated-wild type and UDG knockout mouse models showed $21 \%$ percent more AP sites formed in the former. This comparison suggests a strong correlation between the formation of AP sites and $\left[{ }^{18} \mathrm{~F}\right] \mathrm{FEX}$ uptake. Therefore, the studies above showed $\left[{ }^{18} \mathrm{~F}\right] \mathrm{FEX}$ can effectively evaluate the efficacy of DNA-targeted chemotherapeutic drugs such as pemetrexed. In the imaging studies, only nanomolar $\left[{ }^{18} \mathrm{~F}\right] \mathrm{FEX}$ is needed for PET studies, with no pharmacological effect ever observed in the animal models.

\section{Conclusion}

In summary, FEX was synthesized and evaluated for imaging AP sites in vivo. FEX exhibits a binding property similar to MX. FEX was then radiolabeled with F-18 for in vivo imaging studies. Subsequent $\left[{ }^{18} \mathrm{~F}\right]$ FEX-PET imaging studies in both DLD1 UDG +/+ and knockout tumor mouse models demonstrate its effectiveness for use as an imaging marker of DNA damage and repair for efficacy evaluation of DNA-targeted chemotherapies. In order to enhance its potential for routine clinical studies, particularly in medical facilities without onsite cyclotron, F-18 labeled MX analogs need to be developed that are 
Citation: Zhu W, Wu C, Li Y, Somoza E, Liu L, et al. (2012) In vivo Quantification of Abasic Sites for Efficacious Evaluation of DNA-Targeted Chemotherapies. J Cancer Sci Ther S5:006. doi:10.4172/1948-5956.S5-006

capable of remote distribution.

\section{Acknowledgement}

This work is supported in part by Glennan Fellowship at Case Western Reserve University, Case Comprehensive Cancer Center grant and the Training Program in Cancer Pharmacology (R25 CA1485052).

\section{References}

1. Friedberg EC (2003) DNA damage and repair. Nature 421: 436-440.

2. Barnes DE, Lindahl T (2004) Repair and genetic consequences of endogenous DNA base damage in mammalian cells. Annu Rev Genet 38: 445-476.

3. Fishel ML, Kelley MR (2007) The DNA base excision repair protein Ape1/Ref-1 as a therapeutic and chemopreventive target. Mol Aspects Med 28: 375-395.

4. Damia G, D'Incalci M (2007) Targeting DNA repair as a promising approach in cancer therapy. Eur J Cancer 43: 1791-1801.

5. Parikh A, Gillam EM, Guengerich FP (1997) Drug metabolism by Escherichia coli expressing human cytochromes P450. Nat Biotechnol 15: 784-788.

6. Sawa T, Mameya S, Yoshimura M, Itsuno M, Makiyama K, et al. (1995) Differential mechanism of peptide $Y Y$ and neuropeptide $Y$ in inhibiting motility of guinea-pig colon. Eur J Pharmacol 276: 223-230.

7. Parikh A, Guengerich FP (1998) Random mutagenesis by whole-plasmid PCR amplification. Biotechniques 24: 428-431.

8. Lindahl T (1993) Instability and decay of the primary structure of DNA. Nature 362: 709-715.

9. Rollins KD, Lindley C (2005) Pemetrexed: a multitargeted antifolate. Clin Ther 27: 1343-1382

10. Shepherd FA, Dancey J, Arnold A, Neville A, Rusthoven J, et al. (2001) Phase II study of pemetrexed disodium, a multitargeted antifolate, and cisplatin as first-line therapy in patients with advanced nonsmall cell lung carcinoma: a study of the National Cancer Institute of Canada Clinical Trials Group. Cancer 92: 595-600.

11. Lizzi F, Rosenzweig C (1985) Linearly rising Regge trajectories and bag and string models for hadrons. Phys Rev D Part Fields 31: 1685-1688.

12. Liu L, Schwartz S, Davis BM, Gerson SL (2002) Chemotherapy-induced O(6)benzylguanine-resistant alkyltransferase mutations in mismatch-deficient colon cancer. Cancer Res 62: 3070-3076.

13. Liu L, Yan L, Donze JR, Gerson SL (2003) Blockage of abasic site repair enhances antitumor efficacy of 1,3-bis-(2-chloroethyl)-1-nitrosourea in colon tumor xenografts. Mol Cancer Ther 2: 1061-1066.

14. Rosa S, Fortini P, Karran P, Bignami M, Dogliotti E (1991) Processing in vitro of an abasic site reacted with methoxyamine: a new assay for the detection of abasic sites formed in vivo. Nucleic Acids Res 19: 5569-5574.

15. Atamna H, Cheung I, Ames BN (2000) A method for detecting abasic sites in living cells: age-dependent changes in base excision repair. Proc Natl Acad Sci U S A 97: 686-691.

16. Nakamura J, Walker VE, Upton PB, Chiang SY, Kow YW, et al. (1998) Highly sensitive apurinic/apyrimidinic site assay can detect spontaneous and chemically induced depurination under physiological conditions. Cancer Res 58: $222-225$.

17. Wang Y, Liu L, Wu C, Bulgar A, Somoza E, et al. (2009) Direct detection and quantification of abasic sites for in vivo studies of DNA damage and repair. Nucl Med Biol 36: 975-983.

18. Purohit A, Radeke H, Azure M, Hanson K, Benetti R, et al. (2008) Synthesis and biological evaluation of pyridazinone analogues as potential cardiac positron emission tomography tracers. J Med Chem 51: 2954-2970.

19. Link AJ, Vink MK, Tirrell DA (2007) Synthesis of the functionalizable methionine surrogate azidohomoalanine using Boc-homoserine as precursor. Nat Protoc 2: $1884-1887$.
20. Muzic RF Jr, Cornelius S (2001) COMKAT: compartment model kinetic analysis tool. J Nucl Med 42: 636-645.

21. Chen X, Hui L, Foster DA, Drain CM (2004) Efficient synthesis and photodynamic activity of porphyrin-saccharide conjugates: targeting and incapacitating cancer cells. Biochemistry 43: 10918-10929.

22. Ko YJ, Yun KJ, Kang MS, Park J, Lee KT (2007) Synthesis and in vitro photodynamic activities of water-soluble fluorinated tetrapyridylporphyrins as tumor photosensitizers. Bioorg Med Chem Lett 17: 2789-2794.

23. Yang SI, Seth J, Strachan JP, Gentemann S, Kim D, et al. (1999) Ground and excited state electronic properties of halogenated tetraarylporphyrins. Tuning the building blocks for porphyrin-based photonic devices. J Porphyr Phthalocya 3: 117-147.

24. Zheng X, Pandey RK (2008) Porphyrin-carbohydrate conjugates: impact of carbohydrate moieties in photodynamic therapy (PDT). Anticancer Agents Med Chem 8: 241-268.

25. Adams H, Blanco JL, Chessari G, Hunter CA, Low CM, et al. (2001) Quantitative determination of intermolecular interactions with fluorinated aromatic rings. Chemistry $7:$ 3494-3503.

26. Delbarre A, Brown SC, James TL, Shafer RH (1988) Spectrophotometric and NMR analysis of the interaction of fluorinated mono- and bifunctional intercalators with DNA, poly(dA-dT), and poly(dG-dC). Biopolymers 27: 19531975.

27. Rani-Beeram S, Meyer K, McCrate A, Hong Y, Nielsen M, et al. (2008) A fluorinated ruthenium porphyrin as a potential photodynamic therapy agent: synthesis, characterization, DNA binding, and melanoma cell studies. Inorg Chem 47: 11278-11283.

28. Yan L, Bulgar A, Miao Y, Mahajan V, Donze JR, et al. (2007) Combined treatment with temozolomide and methoxyamine: blocking apurininc/pyrimidinic site repair coupled with targeting topoisomerase Ilalpha. Clin Cancer Res 13 1532-1539.

29. Ingraham HA, Dickey L, Goulian M (1986) DNA fragmentation and cytotoxicity from increased cellular deoxyuridylate. Biochemistry 25: 3225-3230.

30. Van Triest B, Pinedo HM, Giaccone G, Peters GJ (2000) Downstream molecular determinants of response to 5-fluorouracil and antifolate thymidylate synthase inhibitors. Ann Oncol 11: 385-391.

31. Vassylyev DG, Morikawa K (1996) Precluding uracil from DNA. Structure 4 1381-1385.

32. Beard BC, Stevenson JJ, Wilson SH, Smerdon MJ (2005) Base excision repair in nucleosomes lacking histone tails. DNA Repair (Amst) 4: 203-209.

33. Córdoba-Cañero D, Dubois E, Ariza RR, Doutriaux MP, Roldán-Arjona $T$ (2010) Arabidopsis uracil DNA glycosylase (UNG) is required for base excision repair of uracil and increases plant sensitivity to 5-fluorouracil. J Biol Chem 285: 7475-7483.

34. Parikh SS, Mol CD, Slupphaug G, Bharati S, Krokan HE, et al. (1998) Base excision repair initiation revealed by crystal structures and binding kinetics of human uracil-DNA glycosylase with DNA. EMBO J 17: 5214-5226.
This article was originally published in a special issue, Cancer Research: Clinical \& Experimental handled by Editor(s). Dr. Richard D. Finkelman, AstraZeneca LP Clinical, USA; Dr. Jimmy Thomas Efird, University of North Carolina, USA; Dr. Yanming Wang, Case Western Reserve University, USA 